\title{
Prevalence and prognostic significance of right ventricular systolic dysfunction in heart failure with preserved ejection fraction. Insights from a cardiac magnetic resonance imaging study
}

\author{
Stefan Aschauer ${ }^{*}$, Caroline Tufaro, Andreas Kammerlander, Alina F Bachmann, Diana Bondermann,
} Julia Mascherbauer

From 18th Annual SCMR Scientific Sessions

Nice, France. 4-7 February 2015

\section{Background}

Cardiac magnetic resonance imaging (CMR) is the goldstandard technique for the assessment of right ventricular function. Recent data indicate that right ventricular ejection fraction (RVEF) $<45 \%$ by CMR is a strong predictor of outcome in patients with dilated cardiomyopathy. However, the prognostic significance of RVEF in heart failure with preserved ejection fraction (HFpEF) is unknown.

\section{Methods}

Between December 2010 and September 2013 we prospectively enrolled $105 \mathrm{HFpEF}$ patients. At baseline, all patients underwent CMR imaging in addition to invasive and non-invasive testing. Right ventricular systolic dysfunction (RVSD), defined as an RV ejection fraction $<45 \%$, was present in $27(25.71 \%)$ patients. Patients were followed for $434 \pm 325$ days, during which 31 had a cardiac event (hospitalization for heart failure and/or death for cardiac reason).

\section{Results}

By univariate Cox analysis RVSD ( $\mathrm{p}=0.007)$, NYHA class III+IV ( $\mathrm{p}=0.006), 6$-minute-walking-distance $(\mathrm{p}<0.001)$, diabetes $(\mathrm{p}<0.001)$ and mean pulmonary artery pressures $(\mathrm{p}<0.001)$ were significantly associated with outcome. By multivariable analysis only RVSD (HR 3.23, CI 1.50 6.92, $\mathrm{p}=0.003$ ), diabetes (HR 3.51, CI $1.47-8.40 \mathrm{p}=$ 0.005 ) and mean pulmonary artery pressure (HR 1.04, CI $1.00-.108 \mathrm{p}=0.002)$ remained significant predictors

Cardiology, Medical University of Vienna, Vienna, Austria

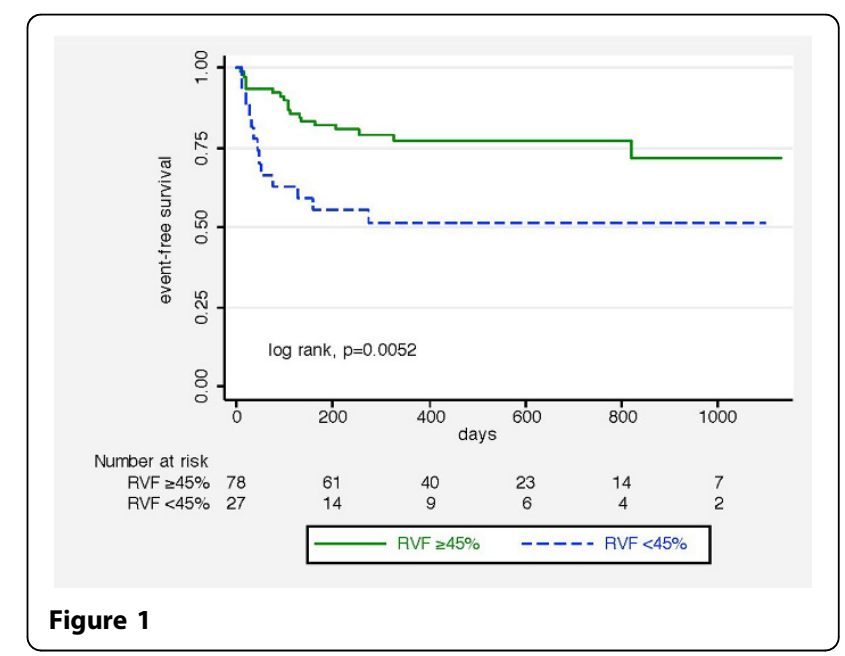

of cardiac events. In addition, patients with RVSD presented with significantly higher resting heart rate $(\mathrm{p}=$ 0.022), more advanced NYHA functional class $(p=0.016)$ and shorter 6-minute-walking-distance ( $\mathrm{t}$-test $\mathrm{p}=0.016$ ). By Kaplan Meier analysis, outcome was significantly worse in patients with RVSD (log rank, $\mathrm{p}=0.0052)$.

\section{Conclusions}

Although HFpEF is considered a disease of the left ventricle respective imaging parameters are not related with outcome. In contrast, RVSD by CMR is significantly associated with mortality and clinical status in these patients, and can be used for risk-stratification. 


\section{Funding}

None.

Published: 3 February 2015

doi:10.1186/1532-429X-17-S1-033

Cite this article as: Aschauer et al:: Prevalence and prognostic

significance of right ventricular systolic dysfunction in heart failure with preserved ejection fraction. Insights from a cardiac magnetic resonance imaging study. Journal of Cardiovascular Magnetic Resonance 201517

(Suppl 1):033.

Submit your next manuscript to BioMed Central and take full advantage of:

- Convenient online submission

- Thorough peer review

- No space constraints or color figure charges

- Immediate publication on acceptance

- Inclusion in PubMed, CAS, Scopus and Google Scholar

- Research which is freely available for redistribution

Submit your manuscript at www.biomedcentral.com/submit

C Biomed Central 